\title{
ECONOMIA E FINANÇAS
}

\section{CAMINHOS DE FERRO EM SÃO PAULO (*)}

\author{
Les chemins de fer semblent véritablement \\ appelés a changer la face du globe.
}

Mich. Chev.

\section{Preliminar.}

II Historico: As primeiras vias ferreas-Concurso financeiro do governo-Organisação $\theta$ admininistração das companhias-Traçados $\theta$ obras d'arte-Dıvisão $\theta$ nomenclatura das linhas.

III Discussão economica: Influencia das estradas na riqueza publiea-A $\theta \mathrm{x}-$ ploração pelo Estado- Capital nacional ou estrangeiro- A questão da reversão -Tarifas $\theta$ trafego mutuo.

IV regislação: Concessões, contractos $\theta$ alterações--Privilegios de zonas.

v Contabilidade : A contadoria central--Sua organisação $\theta$ liquidação de contas.

vI Estatistica: Extensăo, receita e despeza das linhas-Condições technicas.

vII Conclusão

\section{PRELIMINAR}

1) Não constitue objectivo exclusivo deste generico estudo ou antes das succintas informações que vamos reunir-o completo successo dos caminhos de ferro que em S. Paulo, cortando o territorio em todas direcções, ligando pontos extremados, resolveram o problema da circulação de que tanto depende o progresso da riqueza publica.

(*) Müitos dias antes de haver o Snr. Dr. G. Redondo lido na sessão de encerramento do Instituto Historico sua. memoria sobre Estradas de ferro já este artigo estava na typographia. 
No momento presente em que observamos a industria nacional abandonada á mercê dos mais desencontrados accidentes, á voragem de desenfreada especulação, consequente de crise calamitosa; no momento presente em que o nosso organismó industrial se retráhe deante o declinio do credito e a concorrencia estrangeira, parecendo transformar-se em terrivel espantalho da iniciativa particular, do espirito de associação -tudo quanto se possa escrever sobre emprezas industriaes é um protesto contra semelhante ordem de cousas, uma dignificação do trabalho nacional, uma affirmação de que o bem. estar, a prosperidade dos povos têm intimas ligações com a sorte de tão nobres, de tão uteis emprehendimentos.

Assim convencidos e pondo de parte a hesitação que sentimos ao tratar, embora superficialmente daquelle assumpto, delicado como complexo, esforçar-nos-emos em assignalar, a rapidos traços, o papel que n'esta opulenta região têm representado os caminhos de ferro e o facto historico, que os paulistas, como outr'ora os carthaginezes e os romanos, foram dos primeiros que, em nosso paiz, comprehenderam as vantagens tanto do transporte 'como da tracção mechanica, justificando o conceito do velho Rebouças - S. Paulo é a Pensylvania do Brazil! (I).

\section{HISTORICO}

2) Primeiras vias-ferreas. Muitos annos antes da inauguração em 30 de Abril de 1854 da primeira estrada de ferro na America do Sul, denominada Maúa nome glorioso e digno, que o aulicismo subst dos romanos.

(I A Via Appia modelada no typo carthaginez, foi a primeira estrada

Em 1553 o Padre Anchieta abriu a primeira estrada paulista, de Santos aos Campos do Piratininga (São Paulo). 
tuiu pelo actual de Principe do Grão Pará-já a Provincia de São Paulo havia legislado a respeito de tão grande melhoramento, tomando por molde a lei geral n. 100 de 3 I de Outubro de 1835 a primeira que na expressão do Barão Homem de Mello «soli«citou no Brazil o poder da civilisação representado «pela locomotiva».

Ahi estão comprovando o acerto, as celebres leis provinciaes ns. 57 e 5 I de 18 de Março de 1836 sanccionadas pelo Dr. José Cezario de Miranda Ribeiro providenciando a primeira sobre a desapropriação, e a segunda concedendo privilegio exclüsivo a companhia de Aguiar, Viuva e Filhos, Platt e Reidd para «a factura de uma estrada de ferro ou outras de mais «moderna e perfeita invenção ou canaes, ou uma outra "cousa apropriadas ao transito de carros a vapôr e «barcos a vapôr para o transporte de generos desde «a Villa da Constituição (hoje Piracicaba) Itú e Porto «Feliz promptificando em primeiro logar a construcção «pela sobredita maneira—entre á Cidade de S. Paulo «e a Villa de Santos» (2).

Não menos importancia historica tem o decreto I 759 de 26 de Abril de 1856 que approvou as bases para a formação de uma companhia que tinha por objectivo a construcção da Estrada de ferro de Santos a Jundiahy em virtude do privilegio concedido aos illustres brazileiros-Marquezes do Monte Alegre, de S. Vicente e Visconde de Mauá.

Desde então a attenção geral voltou-se para S. Paulo e no reboliço da ideia a iniciativa particular lançou a centelha do progresso promovendo a obra

(2) Este extenso documento de grande valor historico é tambem muito curioso quanto a comprehensão do novo invento e das providencias de simples detalhe da construcção de linha bem como quanto a immigração! 
ingente e renovadora que dia a dia vemos operar grandes transformações e abrir campó á actividade social.

Falamos muito propositalmente da iniciativa paulista por que na alta administração do paiz se reproduzia o mesmo phenomeno da singular hesitação observada em i 830 na França, no momento em que todas as Nações ao redor della multiplicavam os seus caminhos de ferro. (3)

Durante dez annos dependeu da approvação do senado um projecto, preconisado por Tavares Bastos para converter-se na aspiciosa lei de 24 de Setembro de I 873 que concedeu a subvenção kilometrica ou garantia de juros ás companhias de viação ferrea no Brazil, até a quantia de cem mil contos.

$\mathrm{E}$ antes dessa lei, como mais adiante se verifica, S. Paulo, esmagando a rotina e vencendo preconceitos já havia esboçado o seu plano de viação, estēndido ousadamente a sua rede de caminhos de ferro e garantido $7 \%$ simultaneamente ás cinco estradas seguintes: de S. Paulo ao Rio-de Campinas a Limeira e Rio Claro-de S. Paulo ao Ipanema-de Campinas a Mogy e Amparo-de Indayatuba a Capivary e Piracicaba! (4)

3) Não podia ser mais brilhante como acertado o concurso financeiro do governo provincial a essas emprezas que se formavam com capitaes dos agricultores paulistas.

De facto, a confrontação da celebre phrase pronunciada no parlamento nacional e que attesta o espirito da epoca, por occasião da propaganda de viaçẵo

(3) Georges Mayez Les chemins de fer, I89i.Dic. du XIX siécle.

(4) André Reboucas. Estudo sobre Garantia de Juros, i874. A lei provincial sanccionada pelo Dr. José Antonio Saraiva sob n. 495 de I7. de Março de 1855 , garantia $2 \%$ addicionaes a qualquer companhia nacional ou: estrangeira que contractasse com o Governo Imperial a construcção de uma estrada de S. Paulo para o interior. 
ferrea no'Brazil «que a estrada Pedro II, hoje "Central", carregaria em um só dia a producção de um mez inteiro»; do desanimo manifesto de nossos estatadistas que lamentavam a garantia de juros concedida á algumas estradas da Bahia, Pernambuco e S. Paulo-com aquella orientação segura e previsão fecunda, poucos annos depois, das classes dirigentes de S. Paulo, das resoluções de seu governo, se obtem a mais eloquente prova da iniciativa deste povo.

4) Organisação das companhias e sua administração. Excepção feita da Companhia São Paulo Railway todas as mais vias ferreas têm sido organisadas e administradas no paiz.

Da Companhia Ingleza pouco se póde dizer relativamente ao historico de sua constituição, devido de um lado á proverbial parcimonia das emprezas estrangeiras em communicar-se com o publico brazileiro e de outro á dispersão dos documentos officiaes relativos a mesma em nossa legaçăo em Lońdres, no archivo dos ministerios da Agrićultura da União e de S. Paulo e até nos cartorios da Capital Federal, Santos, desta Capital e Jundiahý.

D'ahi a razão do rude conceito de um distincto engenheiro que affirmou em r 888, não haver em nosso paiz nem junto ao seu governo um só homem que tivesse esta, empreza bem estudada!

Sabe-se, entretanto, que esta empreza organisada em Londres teve seus estatutos approvados em I860, época em que se deu começo-á construcção da estrada, quatro annos depois de sua concessão.

Em sua administração observa-se o facto notavel da permanencia do pessoal.

(5) A leí provincial n. 43 de 12 de Julho de 1869 autorisou a Presidencia a tomar acções da Companbia S. Paulo ao Rio de Janeiro até o valor de mil contos de reis-isto quando a receita publica mal attingia ao dobro! 
Seu primeiro presidente foi o 'Sr. Roberto Heath que só deixou o cargo quando morreu, depois de occupal-o durante 20 annos; sendo substituido pelo actual Snr. Martin Smith.

A' frente da gestão administrativa no Brazil tem tido em um periodo de cerca de quarenta annos sómente tres homens, o Snr. Aubertin, o Snr. Fox a que succedeu o Snr. William Speers que, com maxima habilidade, a dirige actualmente.

E' intuitiva e incalculavel a vantagem d'essa estabilidade administrativa que na Inglaterra é norma observada até na sua, alta direcção politica, onde não rare tem havido gabinetes de mais de dez annos de existencia.

Sem essa pratica tão salutar não póde haver conhecimento exacto dos differentes assumptos da administração, nem tradição viva de tantos factos e deliberações, da qual muito depende a boa marcha dos negocios publicos e privados.

E' com prazer que vemos as nossas principaes companhias de viação ferrea imitarem tão salutar exemplo, especialmente no que diz respeito a geral superintendencia do trafego.

Assim ha seguramente mais de dez annos que tem estado á frente da direcção tẹchnica da Sorocabana o Snr. Gêorg Oetterer; da Mogyana o Snr. Dr. A. Brodowsk, recentemente substituido pelo Snr. Dr. Gomide; e da Paulista o Snr. Dr. Torres Neves, havendo outros exemplos infelizmente em contrario como o da extincta companhia Ituana que, em poucos annos teve, oito inspectores!

Ainda na Paulista, ha mais de dez annos, e auxiliar da administração superior na qualidade de chefe do escriptorio central e consultor technico da directoria o Dr. Adolpho Pinto, engenheiro illustre e muito considerado. 
5) Traçadôs e obras d'arte. Parece-nós que no desénvolvimento do plano de viação do Estado de São Paulo predominou o interesse politico sobre as conveniencias de algumas regiōes beneficiadas por esse melhoramento.

Essa convicção é baseada na simples inspecção da carta geographica ou mero confronto do percurso das principaes linhas.

- Quanto a Paulista. E' inegavel que os ricos - municipios de Dous Corregos, Jahú e Banharão sendo forçados a se communicarem com a Capital pela estação. Visconde do Rio Claro ficaram immensamente prejudicados pela longa trajectoria daquella ferro-via.

Centros tão populosos e ferteis deviam ser antes servidos por um prolongamento da «Ituana» cuja żona nesse ponto, ficou inteiramente limitada.

-Quanto a Mogyana. Uma vez chegada á Casa Branca devia seguir directamente por S. José do _Rio Pardo, Mocócá, Franca e Jaguára deixando o trecho do Ribeirão Preto (que aliás é a estação de seu maior movimento) á Paulista por ser verdadeiro prolongamento d'esta.

Este assumpto foi discutido na antiga assembléa provincial paulista e a futura construcção do trecho d'esta ultima estrada denominado «Agua Vermelha» (6) economisando um percurso de mais de cem kilometros ou talvez mais, demonstrará o prejuizo do trian-

(6) Vide a exposição ao Sr.Dr. Bernardino de Campos, presidente do Estado pelo Cons. A. Prado, presidente da Companhia Paulista em 8 de Agosto do corrente anno, e o Relatorio da mesma Companhia de 2 de Abril tambem deste anno.

-O Dr. Torres Neves, em um folheto sob o titulo "De Matto Grosso ao Littoral» apoiando-se nas autoridades do Visconde do Rio Branco, Melgaço, Beaurepere Rohan, Raposo, Buarque de Macedo, Bicalho, Christiano Ottoni e Mello Rego, demonstra brilbantemente que é por Sant'Anna do Parnahyba (ponto terminal deste ramal) que Matto Grosso deve se ligar ao Littoral. 
gulo mineiro ou de toda zona que fica aquem e além do Rio Grande com semelhante traçado.

-Quanto á Sorocabana. Partindo esta linha de S. Paulo devia no ponto mais conveniente bifurcar-se, seguindo um ramo para Itú e margeando sempre o valle do Tieté, outro para Sorocaba, Tatuhy, Itapetininga e outras direcções.

Possam taes erros de traçado servir de ensinamento áquelles que de futuro tenham de construir novas estradas nesta abençoada terra!

- Bem poucas são as obras d'arte dignas de menção nos caminhos de ferro de S. Paulo.

Todavia merecem especial menção o viaducto da Serra de Caldas; a ponte de cerca de 400 metros sobre o Jaguára (Mogyana); as do Piracicaba (Paulista); as do Tieté (Sorocabana); finalmente na Ingleza os planos inclinados e o celebre viaducto de 2 I $5 \mathrm{~ms}$. de comprimento e quasi 50 de altura na serra do Cubatão denominado "grota funda» (7) eque constitúe a obra prima de viação de S. Paulo, verdadeira gloria da engenharia moderna!

6) Divisão e nomenclatura das linhas. Os caminhos de ferro em numero de I 5 existentes actualmente pódem ser divididos em tres grupos:-da União-do Estado-e das associações anonymas subvencionadas ou não pelo governo.

a) Da União. Com o resgate da Estrada de ferro de S. Paulo ao Rio de Janeiro autorisada pelo Decr. 70I de 30 de Agosto de I 890 ficou aquella linha desde 16 de Setembro desse mesmo anno fazendo parte da «Estrada. Central do Brazil» sendo essa

(7) Revista do Instituto Polytechnico de S. Paulo I876 sob a redacção do Dr. Elias Pacheco Jordão. O viaducto da gróta funda foi construido pelo engenheiro Brumlees, 
encorporação importante serviço prestado ao publico pelo snr. General Glycerio, quando ministro d'Agricultura. (8)

Pelo accordo effectuado recebeu a Companhia do Governo Federal 10.000 apolices de conto de reis de $5 \%$ pela alienação da linha que, no ultimo quinquenio, apresentou saldos superiores a quinhentos contos de réis, distribuindo dividendo na rasão de $9 \%$ sobre o capital realisado. (9)

A organisação da «S. Paulo Rio de Faneiro» foi em vista das leis provinciaes de i 9 de Maio de i 862 , 2 I de Abril de i 863, 24 de Abril de 1865 e da de i 2 de Julho de 1869 que autorisou a presidencia a subscrever acções até I.Ooo contos, álém da garantia de juros e das leis 28 de Março de 1870 e 24 de Março de I87I que fixavam a garantia dos juros em $7 \%$ para o capital destinado áquélla estrada de $£$ r.200.000 ou I 0.655:000\$000 ou 46:164\$83+ o kilometro, sendo a demora da constituição definitiva da Companhia devida á questão da navegação do Parahyba por onde se pretendia estabelecer cumulativamente a communicação com o Rio.

Essa companhia contrahio em Londres dois emprestimos na importancia de $764.200 £$ ao juro de $6 \%$, tinha a extensão trafegada de $23 \mathrm{I} \frac{\mathrm{l}}{\mathrm{O}} \mathrm{0} 2 \mathrm{O}$, a bitola de $\mathrm{I}^{\mathrm{m}}$, declividade maxima de $2 \%$, raio das curvas I $22^{\mathrm{m}}$. Seu historico prende-se hoje a "Estrada Central do Brazil».

b) Do Estado. Não ha nenhuma estrada de ferro, propriamente dita, de propriedade do Estado de S. Paulo, que, nesse sentido, tem deixado de alargar seu dominio industrial.

(8) Vide a Exposição de motivos ao Generalissimo Deodoro em 30 de Agosto de I 890.

(9) O Snr. Dr. C. Miranda Jordão por si e por um syndicato offereceu pela Estrada, em Agosto do mesmo anno, 9.209:520\$0oo. 
Todavia não podemos deixar de nos referir ao pequeno caminho de ferro denominado «Tramway Cantareira», da extensão de $\mathrm{I} 3$ kil., pertencente ao Estado e cujo trafego começou em 2 I de `Novembro de I 894 e tende a desenvolver-se á vista da lavoura intensiva á margem da linha, pelos trens de recreio è mais dois minusculos ramaes em construcção para os logares Itaguassú e Pedreira.

c) Das Associações anonymas. Os caminhos de ferro pertencentes ás Associações particulares são os seguintes:-S. Paulo Railway-a Paulista (com a secção da antiga Rio Claro)-a Mogyana-a União Sorocabana e Ituana-a Bragantina - a Itatibense (de Loúveira a Itatiba 20 kil.)-a Viaça Ro Rio e S. Paulo (do Formoso a Bocaina i 8 kil.)-da Bananalense (I I kil.) -a The Rio and Minas (atravessando o territorio paulista numa extensão de 23 kil.) - o Ramal Dumont (23 kil.) -o Ramal Campineiro (33 kil.)--a S. Pauloe Santo Amaro (I 9 kil.) e a Viação Paulista (de Santos a S. Vicente 9 kil.). (I

\section{DISCUSSÃO ECONOMICA}

r) Influencia das estradas de ferro na riqueza publica. Os caminhos de ferro não attestam sómente a civilisação, a fraternidade e o progresso moral de um povo.

Elles são o elemento vital da sociedade, representam a mais brilhante encarnação de capital, uma importante parte da riqueza publica.

Encurtando as distancias, percorrendo com maxima celeridade extensas regiões, desconhecendo os

(Io) Relatorio ao Dr. Jorge Tibiriçá, ministro da Agricultura pelo Dr. José -Rebouças, I 893 . 
obstaculos das elevadas montanhas e dos caudalosos rios, dos vales impraticaveis e dos abysmos profundos - os caminhos de ferro, trazendo a barateza e a segurănça; proporcionando a regularidade, a continuidade e a rapidez do transporte; vencendo finalmente o espaço e ganhando- o tempo; resolveram em toda a parte o grande problema da circulação!

A producção, diz notavel economista, está na rasão geometriça da rapidez da circulação, quanto mais uma nação utiliza o espaço e o tempo mais ella produz (I I) e sendo assim tanto maior será sua riqueza e poder.

Por mais que se queira avaliar como pretendeu outro economista a importancia do serviço que presta a viação ferrea é impossivel chegar-se a uma expressão numerica. (I 2)

Em S. Paulo a lavoura de café encontra nos caminhos de ferro o seu grande escoadouro, o proprietario rural attribue-lhes a valorisação das terras, o operario a permanencia de trabalho e o commercio o crescente movimento de suas transacções pela approximação dos consumidores ao mercado dos negocios.

Como aquilatar-se precisamente a commodidade ou as vantagens dese melhoramento que operou no mundo tão grande revolução?

Influindo directamente os caminhos de ferro na producção e dependendo desta a fixação dos orçamentos e a receita publica - a importancia financeira delles é outra consequencia evidente.

Em S. Paulo, como em outros Estados, as estradas de ferro prestam valioso concurso ás communicações postaeś, á arrecadação de alguns impostos, da qual se incumbem por modica porcentagem, além de

(I I) Yves Guyot La Science Economique.

(I 2) Ad. Coste Nouvel Exp. d'Ec: Polit, r889. M. de Foville. 
outros serviços especiaes como recentemente pelo transporte da força publica e munições bellicas de Santos e desta Capital para o Rio e Itararé, onde em poucos dias o Governo aproveitando-se da posição estrategica de uma das nossas estradas de ferro, poude concentrar cerca de dois mil homens em pé de guerra.

8) A exploração pelo Estado. Não raro temos visto discutir-se a conveniencia do Estado de S. Paulo resgatar alguma de suas ferro-vias, especialmente a Ingleza.

A questão de exploração directa pelo Estado entre nós está porém subordinada a condições especialissimas que não podem deixar de ser ponderadas.

E' verdade que na Prussia, na Belgica, na Austria Ungria, Russia, Dinamarca, Roumania, Suecia e Italia e outros paizes prevalece o regimen da exploração pelo Estado.

A especial organisação do poder administrativo. na Prussia, o intuito politico de libertarem-se as outras nações da pressão do capitalismo adverso, bem como o facto de ser a Europa um acampamento que, da noite para o dia, póde entrar em luta-tudo justifica essa ingerencia governamental.

Nos Estados brazileiros como em toda America do Sul, pondera Leroy Beaulieu não ha probabilidade de guerras com a Europa que a todos fornece seus capitaes.

«E se contra toda a previsão rebentasse um conflicto d'esse genero não poderia ser, a vista da distancia senão exclusivamente naval». ( 1 I 3 )

Seria pois na actualidade summamente prejudicial ao Brazil ou a qualquer dos seus Estados a adju-

(13) Leroy Beaulieu. Artigo para o Jornal do Brazil de 4 de Setembro de I891.-L'Etat moderne et ses fonctions. 
dicação dos caminhos de ferro, cuja administração por conta de Governo tem sido difficil como dispendiosa.

Paiz novo sem possuir numero bastante de profissionaes, atravessando um periodo de reorganisação, é mesmo natural que não apresente resultado satisfatorio n'este campo de especulação industrial.

Dahi o considerarmos de mais vantagem para São Paulo a doutrina contraria que só poderá ser exequivel em futuro assás remoto, quando as condições financeiras o permittirem.

9) Capital nacional ou estrangeiro. Além do ponto de vista politico a que nos referimos, as condições economicas e financeiras de S. Paulo presentemente impedem a exploração dos caminhos de ferro pelo Estado.

Exåminemos, em resumido exemplo, o resgate da Estrada de ferro Ingleza, tão discutido ha pouco tempo pela imprensa diaria da Capital, e que felizmente pelo novo contracto assignado pelo Governo Federal foi éspaçado por mais 30 annos. (I4)

De accordo com o n. I da clausula 36 do Decr. I 759 de 26 de Abril de I 856 o Governo tem a faculdade de desapropriar a estrada e todas suas dependencias. Está calculado que o capital do resgate na conformidade das leis vigentes e dos dividendos distribuidos não seria hoje inferior a 66.000:00o\$ em apolices de $5 \%$ que ao cambio de $24 \mathrm{~d}$. equivalem a 6.600.00o \& ou noutra expressão arithmetica - 57 toneladas de libras sterlinas. (I 5)

- Pretendendo o Governo de S. Paulo realisar tantos melhoramentos materiaes como o saneamento das cidadè̀s do interior, urgindo prestigiar os seus estabe-

(i4). Decr. Federal n. 1999 de 2 de Abril e contracto de I7 de Julho do corrente anno.

(I5) Dr. João Frik. Projecto de resgate offerecido a Assemb. Prov. de S. Paulo em 6 de Fevereiro de 1888. 
cimentos de credito real afim de auxiliarem a lavoura, carecendo proteger a industria nascente, a braços com tã̀o medonha crise-quaes não seriam os desastrados effeitos de uma operação financeira que para aquelle fim immobilisasse grande parte dos recursos ou da fortuna do Estado?

Não podia portanto deixar de ser, presentemente, uma calamidade.

10) A questão da reversão. Muito importa estudar-se e resolver-se a tempo a questão da concessão perpetua ou temporaria das Estradas de ferro, uma vez que o pensamento moderno tem considerado a sua exploração como um serviço publico e não uma obra do interesse privado; uma empreza estreitamente ligada á fortuna da nação, á vida social, (I6)

Combatendo a theoria da reversão inquiria illustre engenheiro:

«Poder-se-á pretender rasoavelmente que no futuro «haja governo tão omnisciente e omnipotente que seja «capaz de exercer simultaneamente com as faculdades «politicas e administrativas as dilatadissimas e mui «variadas funcções que the daria a gerencia universal «das estradas de ferro?».(I 7)

Seria com effeito puerilidade ler no presente em meio dos explendores do progresso humano acontecimentos problematicos do porvir - por outro lado, porém, graves são as arguições em contrario.

A que titulo o nacional ou estrangeiro, concessionario de uma linha ferrea deve para todo o sempre usar, gosar e dispor d'essa propriedade que tambem se compõe de uma grande faixa do territorio por. onde passa-quando o privilegio que disfructou pelo.

(I6) «O Paiz» Edictoriaes de 9 e I I de Junho ultimo.

(I7) Dr. A Rebousas, Obra citada.. 
tempo de tres gerações foi em maior proveito proprio de que da communidade?

Em compensação de tamanho goso, bem como do concurso directo do Estado pela subvenção ou garantia, não é justo subentender-se em todas as concessões a claụsula da reversão ou resgate embora em praso dilatado e remoto?

Infelizmente não vemos asclarecido esse ponto nos contractos do governo paulista com as estradas de ferro ao passo que essa anomalia em outros Estados não se dá.

No Estado do Rio de Janeiro procedeu-se em I 890 um inquerito a respeito e verificou-se que até então attingia á elevada somma de 40.144:00o\$000 o valor da reverssão de suas principaes linhas conforme o contexto de contractos anteriormente lavrados (I 8),

Para nós são indifferentes tanto o regimen da subvenção geralmente adoptado n'aquelle Estado como o da garantia de juros em S. Paulo.

$\mathrm{O}$ que se nos afigura de avisado conselho é que os poderes publicos em S. Paulo, a tempo cogitem de tão magno e intrincado assumpto e dada certa opportunidade, resolvam o problema com toda a serenidade e justiça, sem abdicação de seus direitos naturaes sobre a rede geral de suas communicações por meio dos caminhos de ferro.

11) Tarifas e trafego mutuo. O generoso principio de. «terem os caminhos de ferro tarifas tão baixas, que apenas paguem o seu custeio» é sem duvida grande ideal economico e politico.

(18) Dr. Alberto Brandão Exposição ao Governador do Estado do Rio Gazeta de Noticias de 23 de Março de 189o. Desse documento consta que as estradas de Cantagallo e seus ramaes, S. Izabel do Rio Preto, Grão Pará, Maricá, Araruama, Rio das Flores, Rezende a Areas, S. Anna do Piauhy, S. Antonịo de Padua, Macahé ao Frade, Parahybuna e outras reverterão ao Estado no afim de longo prazo. 
Como judiciosamente pondera Krantz-é pelo serviço que prestam ao povo e não pelos dividendos que distribuem aos accionistas que os caminhos de ferro transformaram a Europa. (I 9 )

Elles são de utilidade social e indispensaveis a obra da solidariedade nacional; não devem pois ficar indefinidamente sob dominio particular.

A realisação d'esse desideratum é entre nós problema que o tempo se encarregará de résolver; emquanto porém pertencerem á associações particulares será injustiça tolher a livre gestão de taes interesses, dignos sem duvida até de protecção.

Relativamente as tarifas esse conceito já teve perffeita applicação.

Com a instabilidade a depressão do cambio ressentio-se a renda liquida das nossas estradas de ferro e isso porque, de um lado a renda bruta se regia por tarifas de transporte fixadas e de outro os preços. dos salarios e do material, combustivel, artigos necessarios para o trafego e conservação das linhas augmentavam a medida que o cambio baixava.

D'ahi resultou entre a receita e a despeza um notavel desinquilibrio que ameaçava a ruina de todas as estradas de ferro quér particulares quér da União. (20)

N'essa emergencia, em vez de fazer-se uma revisão definitiva e geral das tarifas normaes e permanentes o que não se conciliava com a urgencia da providencia - as Companhias vendo diminuirem suas rendas, solicitaram a applicação de uma tarifa movel calcada no molde da da Central de i 892 e mediante outros favores ao publico.

(19) Paulo Courvés Cours d'Ec. Polit. 1893 Pardonnet Notions sur les chemins de fer.

(20) Dr. Fernandes Pinheiro "Tarifa movel» Artigo no Jornal do Commercio de 24 de Dezmbro de 1894. 
Embora de caracter transitorio essa alteração foi permittida a todas Companhias, não havendo mais reducção nos preços das passagens de ida e volta, conșiderando-se os preços em vigor normaes para $0^{\circ}$ cambio de 20 e applicando a taxa addicional de $3 \%$ por dinheiro, abaixo de 20 , para certa tabella, e de $5 \%$ para as demais, excepção feita das de passagem, encommendas, generos alimenticios, machinas, utensilios, é materia prima para industrias.

Limitou-se o augmento até $24 \%$ para aquella tabella e $40 \%$ para as demais, estabelecendo-se tambem que a partir do cambio de 24 d. as companhias terão que reduzir na mesma conformidade do augmento e por dinheiro de elevação, os preços actuaes. (2 I)

Trafego muituo. Não ha duvida, como vulgarmente se diz, que as estradas de ferro só preenchem seus fins como apparelhos de transporte, quando facilitam o transito das mercadorias entre os pontos mais affastados, servidos embora por estradas differentes e até em paizes diversos.

O trafego mutuo, isto é, o transito de mercadorias despachadas com o frete pago ou a pagar atê final destino, aperfeiçoando as relações do commercio e das administrações. não impede ainda que estas liquidem entre si, sem menor prejuizo á parte do trafego que lhes pertencer.

Geraes são as reclamações do commercio contra á exclusão da «Central» d'esse accordo geral em que se acham as demais estradas paulistas e não raro a imprensa tem verberado tão prejudicial anomalia que aliás não se dava na «S. Paulo e Rio de faneiro» por onde transitava facilmente o café despachado do interior para o mercado d'aquella opulenta metropole, (2 2)

(21) Dr. José Rebouças Relat. cit.,

(22) "O trafego mutuo nas estradas Paulistas" Artigo do Jornal do Commercio» de 29 de Janeiro do corrente anno. 
Infelizmente a adopção d'esse utilissimo alvitre tão em voga em todas as linhas ferreas de Europa e dos Estados Unidos tem encontrado muitas difficuldades praticas entre nós, quer pela diversidade do systema das tarifas da "Central: quer pela sua permanente desorganisação devida a causas diversas.

Impossivel será actualmente a «Central» mandar á Contadoria das estradas paulistas as informações e documentos do trafego no prazo de um e dois mezes como effectivamente remettem todas as mais companhias para ter logar a compensação.

Emquanto perdurar essa irregularidade não cessará tambem o prejuizo da propria «Central» e do commercio do Rio que se vê forçado a ter intermediarios em S. Paulo, pagando-lhes $2 \$ 000$ por volume destinado ao interior, onus esse que afinal vae recahir sobre o consumidor.

\section{LEGISLAÇÃO}

12) Concessões contractos e alterações:

- da estrada de ferro Santos a Jundiahy. A lei n. 838 de $\mathrm{I} 2$ de Setembro de 1855 permittiu a construcção de uma estrada de Santo ao Rio Claro sendo por dec. I759 de 26 de Abril de I856 autorisada a encorporação da companhia que deveria levar a effeito a construç̧ão d'essa estrada com garantia de $5 \%$ sobre o capital de $£ 2.000,000$ au qual accresceu-se $£ 650.000$ pelo dec. 2499 de 29 de Outubro de 1859 além da garantia addicional de $2 \%$ da Provincia. Para aquelle fim foi organisada em Londres a companhia sob a denominação de «São Paulo Railway Company Limited» que teve autorisa-

(23) Foreign Railways I 894 Burdett's official intelligence-Dr. Cyro Pessoa «Estradas de ferro no Brasil» 1886. 


\section{$-131 \div$}

ção para funccionar no Brasil por dec. $260 \mathrm{I}$ de $\mathrm{I} .^{\circ}$ de Junho de i 860 . Por dec. 4927 de i 3 de Abril de 1872 foi acceita a desistencia de preferencia ao prólongamento até Rio Claro. Por dec. de I 3 de Maio obteve o favor da ponte no Porto de Santos. De conformidade com o dec. I 999 de 2 de Abril do corrente anno obteve a novação do seu contracto com o Governo Federal em i 7 de Julho ultimo pelo qual se obrigou a construir no prazo de 4 annos uma segunda linhà em duplicação da actual e a realisar outros melhoramentos no transporte.

- Estrada de ferro Paulista. A lei provincial n. 8. de I9 de Maio de 1862 garantio $7 \%$ durante 30 annos para a construcção de uma estrada que fosse de Jundiahy a Campinas só fixando-se no capital de 5.000 contos pela lei provincial de 2 I de Abril de 1863. Organisando-se uma companhia para aquelle fim foram approvados seus estatutos por dec. n. 4283 de 23 de Novembro de i 868 e celebrado o contracto para a construcção da Estrada em 29 de Maio de 1869 com o privilegio de 90 annos. A lei provincial n. 44 de 1869 garantio juros de $7 \%$ sobre capital de 5.000 contos para a construcção de uma linha de Campinas ao Rio Claro, obtendo a «Paulista» essa concessão como seu natural prolongamento em I 2 de Maio de 1873 , sendo então dispensada as garantias de juros. Em $1 . .^{\circ}$ de Maio de 1875 obteve a Companhia a concessão do ramal Mogy-Guassú sem garantia de juros o qual foi inaugurado em $I^{\circ}$ de Abril de 1877. Em I 2 de Junho do mesmo anno foi por contracto approvado pelo governo estabelecido a fusão das tres linhas-Jundiahy a Campinas, Campinas a Rio Claro e de Cordeiros a Mogy Guassú ainda com expressa renuncia das garantias de juros até então obtidas e faculdade da revisão das tarifas. Em 25 de Outubro de i 880 celebrou o contracto 
para a construcção do ramal para Belem do Descalvado. Em 26 de Março de 1892 adquirio finalmente a «Rio Claro» e todo seu acervo por $£ 2.775$,000 em debentures de $5 \%$ preço inferior ao offerecido pela iviogyana (24).

- Estralla Mogyana. A lei n. 28 de 2 I de Março de 1872 garantio $7 \%$ sobre o capital de 3.000 contos a empresa que construisse uma estrada entre Campinas e Mogy-Mirim, com um ramal para o Amparo. Organisada a Companhia Mogyana e approvados seus estatutos por dec. 5 I $37^{-\mathrm{de}}$ I 3 de Novembro de I 8.72 foi-lhe transferido o privilegio daquella linha por 90 annos, e bem assim a concessão de outro por igual prazo para seu prolongamento até a margem do Rio Grande passando por Casa Branca e Franca.

Por lei provincial de 25 de Abril de i 875 foi concedido á Companhia Mogyana o privilegio de zona para a construcção do ramal Ribeirão Preto levando tambem a effeito posteriormente os ramaes entre Jaguary ao Amparo, da Penha e outros que hoje fazem parte, da linha geral.

A mesma Companhia obteve garantia de $7 \%$. do Governo de Minas até o capital maximo de 5.0.00 contos para o prolongamento de estrada em territorio mineiro pela lei provincial n. $279 \mathrm{I}$ de $\mathrm{I} .^{\circ}$ de Outubro de $188 \mathrm{I}$, a zona de 30 kilometros-e bem assim $6 \%$ até o capital de 7.000 contos garantidos pelo

24 Muito se discute ainda esta transacção. A "Rio Claro» primeiramente foi vendida a uma companhia estrangerra por 8.000 contos em dinheiro de contado e por esta transferida á «Paulista» por \& 2.750 .000 a prazo de 30 annos em debentures e com o tempo ver-se-á que esse debito será resgatado pela propria renda da Rio Claro! A "Rio Claro Railway Comp. Limit.» ainda existe em Londres para distribuir os juros das debentures da Paulista. E seu presidente o Snr. Charles Carrengton que publicou curioso relatorio em I6 de Abril ultimo. 
Governo Geral pela lei 3139 de 2I de Outubro de 1882 para seus prolongamentos até Rio Grande e Poços de Caldás.

Effectuou em i 6 de Outubro de 1890 contracto com o Governo Federal para levar a linha do Jaguára a Catalão (Goyaz) e construir ramaes convergentes fixando assim o plano geral d'esta importante arteria que tem uma construcção das mais baratas do Brasil.

- Companhia Sorocabana. A lei provincial n. 34 de 24 de Março de 18.70 concedeu a garantia de $7 \%$ até o capital de 1.200 contos para a construcção de uma Estrada entre Ytú e Sorocaba.

Elevado aquelle capital a 4.000 contos pela lei n. 33 de Março de i87i e determinado que partisse a linha de Ipanema para a Capital tocando em Sorocaba e São Roque--foi organisada a Companhia Sorocabana com aquelle fim.

Approvados os seus estatutos em 24 de Maio do mesmo anno obteve a Companhia o privilegio por 90 annos e a zona de 32 kilometros para e construcção da linha.

Obteve ainda em 20 de Novembro de 1878 o prolongamento de Bacaetava, em 27 de Dezembro de I 879. o de Boituva, em I 3 de Março de 1882 até Itapetininga passando por Tatuhy, e I4 de Janeiro de I 884 o de Tijuco Preto, havendo construido o pequeno trecho de Victoria para unir-se a Ituana.

Pelo contracto celebrado com o Governo do Estado em a 24 de Maio de 1892 esta companhia tornou effectiva a sua fusão com a Ituana com a expressa renuncia da garantia de juros para ambas.

13) Privilegio de zonas. O augmento da população e a expansão commercial nestes ultimos annos 
demonstraram effectivamente os graves erros das administrações do antigo regimen com relação a este importante assumpto.

Com a mesma liberalidade que o poder central garantia irreflectidamente juros á estradas cujo custo do kilometro excedeu de cem contos de réis, assim tambem agiam as Provincias na questão de determinação das zonas, sem o menor conhecimento prévio das condições economicas e sociaes e topographicas das differentes regiões (25).

D'ahi o incalculavel prejuizo da lavoura tão ferida em seus interesses por essa mal entendida protecção á industria de transporte.

Proclamada a Republica coube ao espirito democratico dos paulistas representado na iniciativa do Dr. Bueno de Andrade, decretar a lei n. 30 de r 2 de Junho de 1892 que, uma vez por todas, veio fazer desapparecer tão grave imperfeição no systema de viação.

Eșse notavel acto do Congresso paulista entre outras saudaveis disposições, fixou em $100,{ }^{\mathrm{m}} \mathrm{OO}$ de cada linha, contados do eixo do leito á zona das estradas de ferro respeitados os direitos adquiridos em virtude de anteriores contractos.

Essa util ideia encontrou franco apoio no Estado de Minas onde o Dr. Cypriano de Carvalho, director geral das obras publicas demonstrou pela imprensa da capital mineira os nobres intuitos e vantagens praticas de uma reforma n'esse sentido (26).

$25 \mathrm{O}$ art. $1 \mathrm{I}^{\circ} \S 44^{\circ}$ da lei de $185_{2}$ é o primeiro acto sobre a zona privilegiada no Brasil. O Reg. que baixou com o dec. 5564 de 28 de Fevereiro de 1874 , fixou o maximo de 30 kilometros de um e outro lado da es: trada para tal zona. O Dec. 29 de Dezembro de 1890 reduziu essa extensão a 20 kilometros no maximo, limitada a zona por duaš linhas parallelas ao eixo da primitiva estrada.

(26) Edictoriaes do "Estado de Minas》 de Julho de 1893. 
Assim dizia aquelle digno funccionario: «jamais deverá o privilegio de zona, para estradas de ferro, ser concedido por fórma a embaraçar ou obstar a construcção de ramaes e prolongamentos, ainda mesmo com estação na propria zona privilegiada; providencia que aliás tornar-se-ia desnecessaria desde o dia em que a zona privilegiada não excedesse de dez kilometros para cada lado do eixo da linha.»

No Estado do Rio um projecto ápresentado pelo deputado Dr. Americo Wernek e outros, calcado no mesmo molde fni posteriormente votado (I 894) ficando ali delimitada a zona de doze kilometros de lado a lado para as futuras estradas de ferro.

Foi portanto incontestavelmente uma notavel reforma levada a effeito no systema de viação' d'estes Estados e que muito honra o regimen democratico das novas instituições republicanas.

\section{CONTABILIDADE}

14) A Contadoria Central. Em i 874 em seu relatorio aos accionistas assim se exprimio a Direc-. toria da Companhia Paulista:

Estamos deante de uma difficuldade que só tem duas sahidas: ou isolar as companhias e cortar completamente as relaçães economicas entre ellas para evitar a promiscuidade de contas, ou crear-se um systema de tarifas que facilite a divisão da receita na rasão do percurso.

O primeiro systema é tão vexatorio para o publico, tão prejudicial mesmo para as companhias que nem merece discussão. Si cada uma das estradas de ferro da provincia, importasse uma viagem separada e distincta o passageiro ou mercadoria que sahisse do Amparo por exemplo, e que fosse parar em Sorocaba 
teria quatro viagens á realisar: uma na estrada Mogyana até Campinas; outra na Paulista até Jundiahy, outra na estrada Ingleza até S. Paulo; outra finalmente na estrada Sorocabana até Sorocaba. Tudo isto com as competentes fadigas de despachos, desembarques, novos despachos e desembarques, sujeitos: a demora, augmento de despeza pela necessidade de intermediarios, etc., o que tudo significa um systema. prohibitivo.

Se nós pela diversidade de bitolas não podemos fugir completamente d'esses inconvenientes porque as baldeações são inevitaveis, é já muito conseguir minorar os males pelos despachos directos, quer de passageiros quer de mercadorias da uma estação de qualquer das estradas para qualquer estação de outra ainda mais longinqua.

Eis a summa dos motivos que determinaram a creação de uma das mais brilhantes instituições das Estradas de Ferro Paulistas e que se denomina "Contadoria Central» ou antes a "Railway Clearing-house Paulista» modelada em identica instituição ingleza fundada em i 842 que abrange 97 companhias e que tanta honra faz ao grande engenho dos seus creadores-Stephenson e Morrison.

15) Sua organisação e liquidação de contas. Fundada. em I 5 de Abril de i 875 para facilitar as relações do trafego entre as diversas estradas paulistas funcciona a Contadoria Central nesta Capital. Tivemos occasião de visitar essa repartição uma das mais bem organisadas que conhecemos já pela disciplina do pessoal já pela regularidade da distribuição do serviço o que muito honra a direcção do Dr. Ignacio W. G. Cochrane, e Francisco Mündell.

$\mathrm{Na}$ conformidade de seu regulamento interno de 31 de Agosto de 1893 approvado em reunião das 
Estradas, n'aquella data, temı por fim essa utilissima instituição:-liquidar as contas do trafego reciproco das Estradas e a regularisação das mesmas quanto a uniformidade de tarifas em tanto quanto' for compativel com as condições especiaes das mesmas. Fazem parte d'esta Clearing hause Paulista as estradas--Ingleza - Paulista-Mogyana - Sorocabana e YtuanaBragantina-Itatibense e Campineira, excepção feita da «Central» anomalia essa a que já nos referimos.

Conforme o ultimo relatorio a. importancia do trafego liquidado foi o seguinte:

IMPORTANCIA DO TRAFEGO LIQUIDADO:

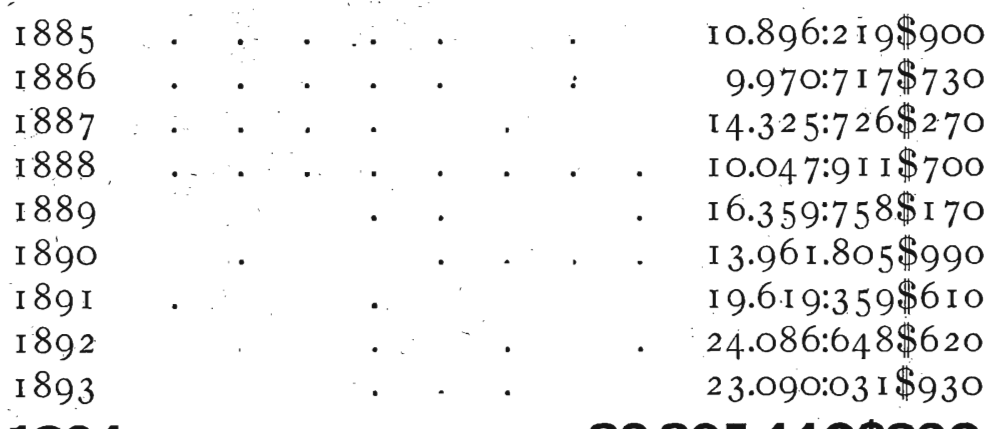

$1894 \quad$. . . $\quad 32.395: 440 \$ 820$ 


\section{ESTATISTICA}

15) $O$ quadro seguinte representa a extensão, receita e despeza, das principaes estradas de ferro conforme os dados officiaes constantes do relatorio apresentado em 3 de Março do corrente anno ao Presidente do Estado Dr. Bernardino de Campos pelo Dr. Jorge Tibiriçá.

Caminhos de ferro em S. Paulo durante 0 anno de 1894

\begin{tabular}{|c|c|c|c|c|c|}
\hline Designações & $\begin{array}{l}\text { N. de } \\
\text { kil. em } \\
\text { trafegego }\end{array}$ & Receita & Despeza & Saldo & $\begin{array}{c}\text { Relaçáno } \\
\text { da despeza } \\
\text { para a } \\
\text { receita }\end{array}$ \\
\hline $\begin{array}{l}\text { S. Paulo Railway } \\
\text { Comp. (24) }\end{array}$ & & & & & \\
\hline $\begin{array}{l}\text { Comp. (24) } \\
\text { Comp. Paulista }\end{array}$ & 139 & 14.303:238\$u30 & $5.756: 411 \$ 740$ & $8.546: 826 \$ 290$ & $40,05 \%$ \\
\hline $\begin{array}{l}\text { Comp. Paulista (25) } \\
\text { Comp. Mogyana. }\end{array}$ & 952 & $13.930: 095 \$ 020$ & $5.601: 166 \$ 380$ & $8.329: 442 \$ 159$ & $40 ; 21 \%$ \\
\hline $\begin{array}{l}\text { Comp. Mogyana. } \\
\text { Comp. Sorocabana }\end{array}$ & 935 & $10.197: 979 \$ 580$ & $7.330: 069 \$ 105$ & $2.867: 910 \$ 475$ & $71,87 \%$ \\
\hline Ituana (26) . & 856 & $5.026: 694 \$ 250$ & $2.847: 039 \$ 810$ & $2.179: 654 \$ 440$ & $56,63 \%$ \\
\hline Comp. Bragantina . & 52 & $275: 977 \$ 430$ & $299: 451 \$ 897$ &.$\quad \therefore$ & $108,50 \%$ \\
\hline Comp. Itatib & 20 & $65: 563 \$ 980$ & $39: 406 \$ 723$ & $26: 187 \$ 267$ & $60,67 \%$ \\
\hline Counp. Campineira. & 43 & $168: 906 \$ 875$ & 171:462\$63் & & $101,51^{\circ}$ \\
\hline
\end{tabular}

(24) Não estão comprehendidas as despezas -da administração em Londres.

(25) Tem 200 kil. de navegação fluvial.

(26) Tem 220 » » » 
16) O quadro segundo apresenta os dados completos dos caminhos de ferro em trefego e suas condições technicas: (26)

\begin{tabular}{|c|c|c|c|c|c|}
\hline : & $\begin{array}{l}\text { Nome da Companhia ou } \\
\text { Estrada de Ferro }\end{array}$ & Bitola & 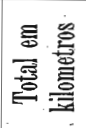 & $\begin{array}{c}\text { Raios } \\
\text { minimos }\end{array}$ & $\begin{array}{l}\text { Declividade } \\
\text { maxima por } \\
\text { metro }\end{array}$ \\
\hline $\begin{array}{r}9 \\
10 \\
11 \\
12 \\
13 \\
14 \\
15\end{array}$ & $\begin{array}{l}\text { Estrada de F. Central do Brazil } \\
\text { Idem Idem. } \\
\text { S. Paulo Ralwav e C. } \\
\text { Comp. Paulista de Vias Fer- } \\
\text { reas e Fluviaes } \\
\text { Idem Idem (antiga Rio Claro) } \\
\text { Idem Idem (Descalvadense e } \\
\text { Santa Rita) } \\
\text { Companhia Mogyana } \\
\text { Idem Idem } \\
\text { Companhia Enião Sorocabana } \\
\text { e Ituana } \\
\text { Idem Idem (Ituana) } \\
\text { Companhia Bragantina } \\
\text { Idem Itatibense } \\
\text { Idem Via(ão Rio e S. Paulo } \\
\text { (antiga Rezende a Bocaina) } \\
\text { Estrada de F. Bananalense } \\
\text { The Minas and Rio Ralway } \\
\text { e C. a . . . . . } \\
\text { Ramal Ferreo Dumont } \\
\text { Companhia Ramal Ferreo Cam- } \\
\text { pineiro } \\
\text { Companhia Carris de Ferro de } \\
\text { S. Paulo a Santo Amaro } \\
\text { Companhia Viação Paulista } \\
\text { Tramway aos Reservatorios } \\
\text { da Cantareira }\end{array}$ & $\begin{array}{c}\mathrm{m} \\
1,60 \\
1,00 \\
1,60 \\
1,60 \\
1,00\end{array}$ & $\begin{array}{r}41 \\
767 \\
41 \\
\\
356 \\
280 \\
52 \\
20\end{array}$ & $\begin{array}{r}181,04 \\
119,93 \\
241,31 \\
300,03 \\
119,92 \\
40,00 \\
100,10 \\
50,00 \\
80,00 \\
120,00 \\
120,00 \\
80,00 \\
100,00 \\
80,00 \\
80,00 \\
60,07 \\
64,00 \\
57,00 \\
16,00 \\
6,000\end{array}$ & $\begin{array}{l}0,018 \\
0,020 \\
0,025 \\
0,020 \\
0,025 \\
0,030 \\
0,030 \\
0,030 \\
0,020 \\
0,028 \\
0,027 \\
0,025 \\
0,025 \\
0,0125 \\
0,030 \\
0,030 \\
0,030 \\
0,025 \\
0,015 \\
0,0325\end{array}$ \\
\hline
\end{tabular}

- (26) Faltam-nos informações sobre o ramal Santa Etelvina, ha pouco construido, de percurso de 13 kilometros, e que vae da Estação do Lageado á fazenda daquelle nome de propriedade do Snr. Coronel A. Proost Rodovalho. 
Em summa:

O Estado de S. Paulo possue actualmente;

I 5 estradas em trafego com um total de 2.883 kil.

$\left.\begin{array}{rl}6 & \text { I } 3 \text { em construcção } \\ \text { contractadas }\end{array}\right\}$ com um total de 2.000 \%

Um percurso total que em breve tempo elevarse-á a cerca de 5.000 kilometros!

\section{CONCLUSÃO}

Os estreitos limites de um artigo não permittem, embora no terreno da generalidade, o estudo de outras questões actuaes concernentes á tão bello assumpto.

Entre ellas ahi estão;---as novas estradas de S. Paulo ao Rio Grande do Sul, de Taubaté a Ubatuba e Santos, a debatida questão da bitola (27) a falta de instituições de previdencia para os multiplos accidentes, a exigua relação entre as reservas para a reconstrucção, material das linhas e seus avultados capitaes, o infimo valor em que estão sendo cotadas as acções das mesmas estradas de ferro nas proximidades de abundante colheita e finalmente tantas outras que são diariamente objecțo das mais empenhadas discussões.

Um exame, ainda mesmo sobre pontos capitaes de assumptos de tamanha monta, exigiria tempo que nos falta para a consulta de um sem numero de documentos, não raro esparsos e difficeis de ser encontrados.

D'ahi, o remate d'este imperfeito trabalho sobre os caminhos de ferro em S. Paulo que tão justamente

(27) O Dr: Ozorio de Almeida iniciou recentemente a discussão d'este assumpto no qual tomavam parte os mais notaveis engenheiros do Brazil. 
tem attrahido a admiração do paiz para este póvo, modelo de iniciativa, em todos emprehendimentos da civilisação.

Affirmando essa verdade dizia um profissional de alta competencia no Brazil:-é em S. Paulo que o espirito americano ostenta-se no arrojo das emprezas e no explendor dos resultados. $E^{\prime}$ ahi que a phrase de Pelletan encontra restricta applicação-le monde marche (28).

E nem se diga acrescentamos nós, ser banal tão elevado conceito.

Eis o que lemos algures:--a modestia, qualidade nos individuos, é inadmissivel nas nações. $\mathrm{O}$ patriotismo deve sempre vibrar a fibra da vaidade, do amor proprio, da alteneria e jamais a subalternidade nacional. $O$ orgulho de um povo deve ser desenvolvido e propagado. Com esse orgulho superam as nacionalidades crises mortaes. Aviltam-se sem elle. E' meio caminho para a grandeza: uma das azas do progresso e da gloria!

- S. Paulo, 3 de Novembro de I 895.

$$
\begin{gathered}
\text { Dr. Foão Sedro da Weiga Filho } \\
\text { Lente substituto da Faculdade }
\end{gathered}
$$

(28) J. Ewbank da Camara «Os caminhos de ferro de S. Paulo» 1894. 